University of Wollongong

Research Online

Australian Institute for Innovative Materials -

Papers

Australian Institute for Innovative Materials

$1-1-2015$

Large entropy change accompanying two successive magnetic phase transitions in TbMn2Si2 for magnetic refrigeration

\author{
Guoxing Li \\ University of Wollongong, Jilin University \\ Jianli Wang \\ University of Wollongong, jianli@uow.edu.au \\ Zhenxiang Cheng \\ University of Wollongong, cheng@uow.edu.au \\ Qing Yon Ren \\ University of New South Wales \\ Chunsheng Fang \\ University of Wollongong, cf904@uowmail.edu.au
}

See next page for additional authors

Follow this and additional works at: https://ro.uow.edu.au/aiimpapers

Part of the Engineering Commons, and the Physical Sciences and Mathematics Commons

Research Online is the open access institutional repository for the University of Wollongong. For further information contact the UOW Library: research-pubs@uow.edu.au 


\title{
Large entropy change accompanying two successive magnetic phase transitions in TbMn2Si2 for magnetic refrigeration
}

\author{
Abstract \\ Structural and magnetic properties in $\mathrm{TbMn}_{2} \mathrm{Si}_{2}$ are studied by variable temperature X-ray diffraction, \\ magnetization, electrical resistivity, and heat capacity measurements. $\mathrm{TbMn}_{2} \mathrm{Si}_{2}$ undergoes two \\ successive magnetic transitions at around $T_{c 1}=50 \mathrm{~K}$ and $T_{c 2}=64 \mathrm{~K} . T_{c 1}$ remains almost constant with \\ increasing magnetic field, but $T_{c 2}$ shifts significantly to higher temperature. Thus, there are two partially \\ overlapping peaks in the temperature dependence of magnetic entropy change, i.e., $-\Delta S_{M}(T)$. The \\ different responses of $T_{c 1}$ and $T_{c 2}$ to external magnetic field, and the overlapping of $-\Delta S_{M}(T)$ around $T_{C 1}$ \\ and $T_{c 2}$ induce a large refrigerant capacity $(R C)$ within a large temperature range. The large reversible \\ magnetocaloric effect $\left(-\Delta S_{M}{ }^{\text {peak }}=\right.$ approx. $16 \mathrm{~J} / \mathrm{kg} \mathrm{K}$ for a field change of 0-5 T) and RC $(=396 \mathrm{~J} / \mathrm{kg})$ \\ indicate that $\mathrm{TbMn}_{2} \mathrm{Si}_{2}$ could be a promising candidate for low temperature magnetic refrigeration.

\section{Keywords} \\ accompanying, large, change, refrigeration, tbmn2si2, transitions, phase, magnetic, successive, two, \\ entropy \\ Disciplines \\ Engineering | Physical Sciences and Mathematics

\section{Publication Details} \\ Li, G., Wang, J., Cheng, Z., Ren, Q., Fang, C. \& Dou, S. (2015). Large entropy change accompanying two \\ successive magnetic phase transitions in $\mathrm{TbMn}_{2} \mathrm{Si}_{2}$ for magnetic refrigeration. Applied Physics Letters, \\ 106 (18), 182405-1-182405-5.

\section{Authors} \\ Guoxing Li, Jianli Wang, Zhenxiang Cheng, Qing Yon Ren, Chunsheng Fang, and S X. Dou
}




\title{
Large entropy change accompanying two successive magnetic phase transitions in $\mathrm{TbMn}_{2} \mathrm{Si}_{2}$ for magnetic refrigeration
}

\author{
Guoxing Li, ${ }^{1}$ Jianli Wang, ${ }^{1,2, a)}$ Zhenxiang Cheng, ${ }^{1, a)}$ Qingyong Ren, ${ }^{3}$ Chunsheng Fang, ${ }^{1}$ \\ and Shixue Dou ${ }^{1}$ \\ ${ }_{1}^{1}$ Institute for Superconducting and Electronic Materials, University of Wollongong, Wollongong, \\ New South Wales 2522, Australia \\ ${ }^{2}$ Bragg Institute, Australian Nuclear Science and Technology Organization, Lucas Heights, \\ New South Wales 2234, Australia \\ ${ }^{3}$ School of Physical, Environmental and Mathematical Sciences, University of New South Wales, \\ Canberra, Australian Defence Force Academy, ACT 2600, Australia
}

(Received 24 March 2015; accepted 26 April 2015; published online 5 May 2015)

\begin{abstract}
Structural and magnetic properties in $\mathrm{TbMn}_{2} \mathrm{Si}_{2}$ are studied by variable temperature X-ray diffraction, magnetization, electrical resistivity, and heat capacity measurements. $\mathrm{TbMn}_{2} \mathrm{Si}_{2}$ undergoes two successive magnetic transitions at around $\mathrm{T}_{\mathrm{c} 1}=50 \mathrm{~K}$ and $\mathrm{T}_{\mathrm{c} 2}=64 \mathrm{~K}$. $\mathrm{T}_{\mathrm{c} 1}$ remains almost constant with increasing magnetic field, but $\mathrm{T}_{\mathrm{c} 2}$ shifts significantly to higher temperature. Thus, there are two partially overlapping peaks in the temperature dependence of magnetic entropy change, i.e., $-\Delta S_{M}(T)$. The different responses of $T_{c 1}$ and $T_{c 2}$ to external magnetic field, and the overlapping of $-\Delta S_{M}(T)$ around $T_{c 1}$ and $T_{c 2}$ induce a large refrigerant capacity $(R C)$ within a large temperature range. The large reversible magnetocaloric effect $\left(-\Delta \mathrm{S}_{\mathrm{M}}{ }^{\text {peak }} \sim 16 \mathrm{~J} / \mathrm{kg} \mathrm{K}\right.$ for a field change of $0-5 \mathrm{~T})$ and $\mathrm{RC}(=396 \mathrm{~J} / \mathrm{kg})$ indicate that $\mathrm{TbMn}_{2} \mathrm{Si}_{2}$ could be a promising candidate for low temperature magnetic refrigeration. (C) 2015 AIP Publishing LLC.
\end{abstract}

[http://dx.doi.org/10.1063/1.4919895]

Magnetic refrigeration is a cooling technology based on the magnetocaloric effect (MCE), which is an intrinsic phenomenon of many magnetic materials. In the last two decades, the magnetic materials with large/giant MCE have been extensively studied experimentally and theoretically due to the high efficiency and eco-friendliness of magnetic refrigeration compared to the commonly used gas compression technique. ${ }^{1-8}$ The isothermal magnetic entropy change $\left(-\Delta S_{M}\right)$ or adiabatic temperature change $\left(\Delta \mathrm{T}_{\mathrm{ad}}\right)$ under a varying magnetic field is the key performance indicator of magnetic cooling materials. Searching for magnetic materials with large values of $-\Delta \mathrm{S}_{\mathrm{M}} / \Delta \mathrm{T}_{\mathrm{ad}}$ has been considered as the main task in this field during the last few years. A number of magnetic materials with large values of $\Delta \mathrm{S}_{\mathrm{M}} / \Delta \mathrm{T}_{\mathrm{ad}}$ accompanied by a first order phase transition have been reported. ${ }^{9-15}$ Nevertheless, only some of them, especially rare-earth-based intermetallic compounds, ${ }^{16-21}$ have a small hysteresis loss, which is desirable for practical application. In addition, large reversible MCEs only appear in a small temperature range for most of the rare-earth-based intermetallic compounds. This means that the corresponding refrigerator could only work well within a small range of temperature. An ideal magnetic Ericsson refrigeration cycle should be based on a material with large and constant $-\Delta \mathrm{S}_{\mathrm{M}} / \Delta \mathrm{T}_{\mathrm{ad}}$, as a function of temperature over the whole refrigeration range, (known as "table-like" MCE). Such materials include $\mathrm{Eu}_{4} \mathrm{PdMg}$, $\mathrm{Eu}_{8} \mathrm{Ga}_{16} \mathrm{Ge}_{30}-\mathrm{EuO}$, and HoPdIn. ${ }^{19-21}$ Therefore, it is important to search for materials that exhibit giant/large MCE not only with small hysteresis loss but also with a wide temperature range.

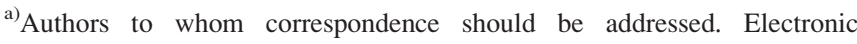
addresses: jianli@uow.edu.au and cheng@uow.edu.au.
}

During the last few years, some $R T_{2} X_{2}$ compounds ( $R=$ rare earth, $T=$ transition metal, and $X=\mathrm{Si}$ or $\mathrm{Ge}$ ) have been found to possess not only large MCE but also a small hysteresis loss around their ordering temperature. ${ }^{22}$ The $R \mathrm{Mn}_{2} X_{2}$ series $(X=\mathrm{Si}$ and $\mathrm{Ge})$ crystallize in the bodycentered tetragonal $\mathrm{ThCr}_{2} \mathrm{Si}_{2}$-type structure (with space group $14 / \mathrm{mmm}),{ }^{23,24}$ with its series of atomic layers stacked along the $c$-axis (similar to $R_{5}(\mathrm{Si}, \mathrm{Ge})_{4}$, a family of wellknown large MCE materials ${ }^{1}$ ), which can offer scope for selection of the magnetic state-and therefore the MCE-by controlling the interlayer and intralayer distances between magnetic atoms.

The magnetic structure of $\mathrm{TbMn}_{2} \mathrm{Si}_{2}$ was well studied using neutron diffraction twenty years ago. ${ }^{25,26}$ It displays the classical first order phase transition, and has two phase transition temperatures located at about 50 and $70 \mathrm{~K}$. Two adjacent magnetic phase transitions may make this material display large $-\Delta \mathrm{S}_{\mathrm{M}} / \Delta \mathrm{T}_{\mathrm{ad}}$ over a wide temperature range, although there have been only a few reports on the MCE in $\mathrm{TbMn}_{2} \mathrm{Si}_{2} \cdot{ }^{18}$ In order to achieve a complete understanding of $\mathrm{TbMn}_{2} \mathrm{Si}_{2}$, in this paper, we studied the magnetic properties of this compound, especially its MCE property using variable temperature $\mathrm{X}$-ray diffraction, together with magnetic and specific heat measurements.

The sample used in the research for this report is a piece of polycrystalline $\mathrm{TbMn}_{2} \mathrm{Si}_{2}$ bulk obtained by argon arc melting appropriate amounts of high purity elements on a watercooled $\mathrm{Cu}$ hearth with a Tb:Mn:Si molar ratio of 1:2:2. Around 3\% excess Mn was added to compensate for loss during melting process. The sample was characterized by x-ray powder diffraction (XRD) measurements (20-300 K) using a PANAlytical diffractometer with $\mathrm{Cu}-\mathrm{K} \alpha$ radiation to evaluate the crystal structure and clarify the temperature dependence 


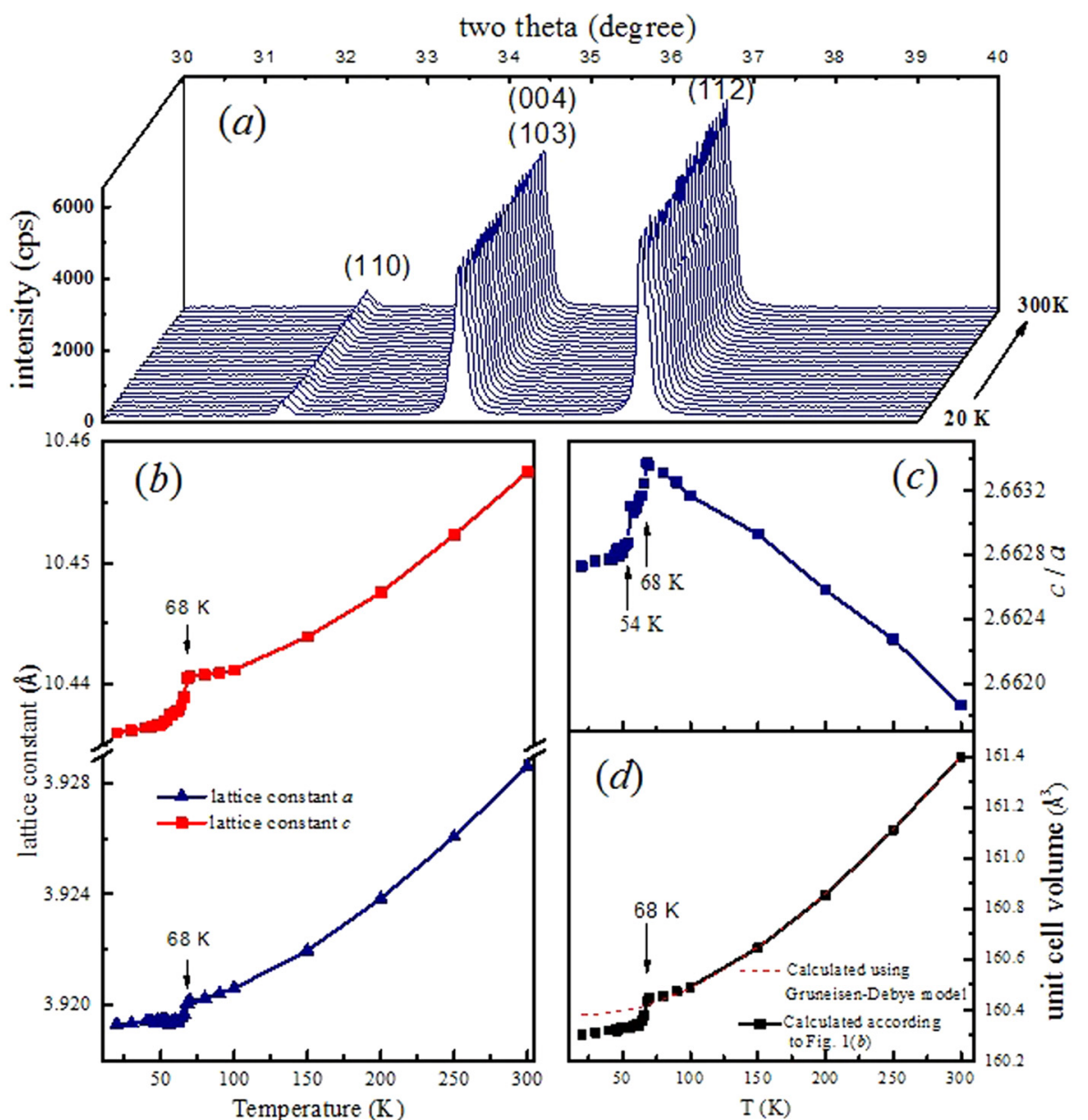

FIG. 1. Crystal structure according to XRD of $\mathrm{TbMn}_{2} \mathrm{Si}_{2}$ at different temperatures: (a) XRD patterns at temperatures of $20,30,40,42,44,46,48,50$, $52,54,56,58,60,62,64,66,68,70$, $80,90,100,150,200,250$, and $300 \mathrm{~K}$; (b) temperature dependence of the lattice constants $a$ and $c$ according to the refined XRD patterns of (a); (c) temperature dependence of the lattice constant ratio $c / a$; and (d) temperature dependence of the unit cell volume of $\mathrm{TbMn}_{2} \mathrm{Si}_{2}$. of the lattice constant around the critical temperatures. The Rietveld refinements were carried out using the Fullprof ${ }^{\circledR}$ program. The magnetic measurements, including temperature dependent magnetization curves and magnetization-field loops around its magnetic transition temperature, were measured on a Quantum Design 9 T physical properties measurement system (PPMS). The transport property in magnetic fields was measured using a standard four-probe method in the same PPMS machine. Heat capacity measurements were conducted on a Quantum Design $14 \mathrm{~T}$ physical properties measurement system.

As shown by the series of XRD patterns in Figure 1(a), $\mathrm{TbMn}_{2} \mathrm{Si}_{2}$ sample is confirmed to be single phase with a body-centered tetragonal structure (space group $14 / \mathrm{mmm}$ ) over the temperature range from 20 to $300 \mathrm{~K}$. There is no detectable crystal structure change over this temperature range, but obviously, the lattice constants $a$ and $c$ were found to display discontinuity around $68 \mathrm{~K}$ on top of a smooth increasing trend with temperature (Figure 1(b)) Moreover, as shown in Figures 1(c) and 1(d), further analysis with respect to change in the unit cell shape shows that lattice constant ratio $c / a$ increases sharply without apparent volume change at $54 \mathrm{~K}$, but with obvious volume change at $68 \mathrm{~K}$. Undoubtedly, these bumps or jumps in Figures 1(b)-1(d) are not following the trend of the thermal expansion of lattice vibrations with temperature. In order to estimate the spontaneous magnetic striction giving rise to this anomaly, the lattice thermal expansion was calculated using the Grüneisen-Debye model, shown as the dashed line in Figure 1(d), ${ }^{27,28}$ with a Debye temperature of $320 \mathrm{~K}$ and extrapolated from the higher temperature region (based on the fact that the magnetic contribution in the antiferromagnetic region to total thermal expansion can be ignored for these types of compounds). ${ }^{22}$ It can be clearly seen that magnetic contributions are obvious around $68 \mathrm{~K}$.

The temperature dependence of the magnetization is presented in Figure 2(a), with the two critical temperatures

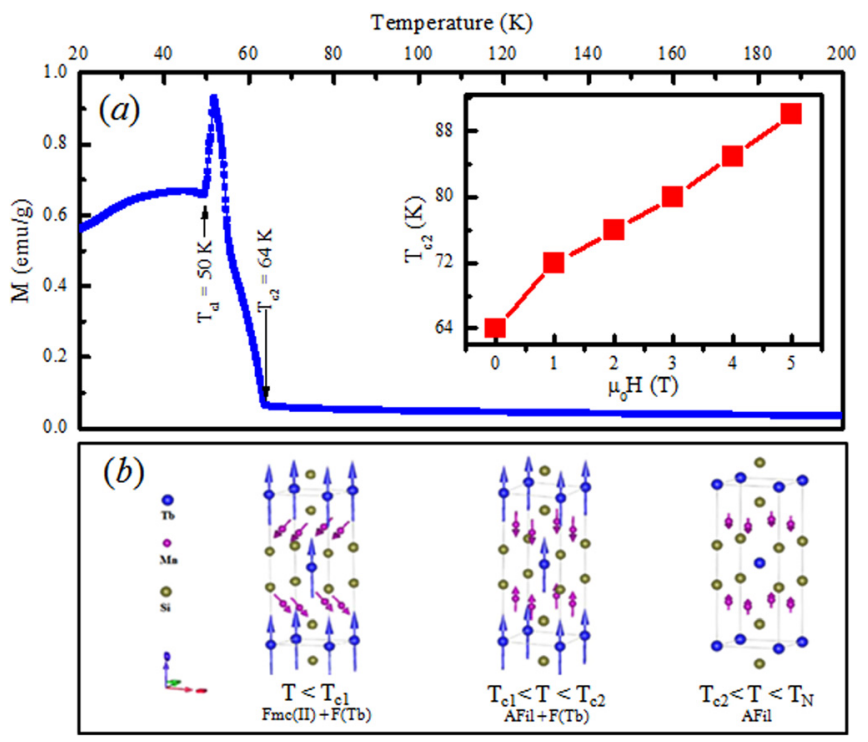

FIG. 2. (a) Magnetization as a function of temperature measured under a field of $\mu_{0} \mathrm{H}=0.01 \mathrm{~T}$. The inset shows the field dependence of $\mathrm{T}_{\mathrm{C} 2}$. (b) Schematic diagram of the magnetic structure of $\mathrm{TbMn}_{2} \mathrm{Si}_{2}$. 
identified: $\mathrm{T}_{\mathrm{c} 1}(\approx 50 \mathrm{~K})$ and $\mathrm{T}_{\mathrm{c} 2}(\approx 64 \mathrm{~K})$. The $\mathrm{M}$-T curves under different magnetic fields have been obtained and show clearly that $\mathrm{T}_{\mathrm{cl}}$ remains almost constant as the field changes from 0 to $5 \mathrm{~T}$, while $\mathrm{T}_{\mathrm{c} 2}$ is driven to higher temperature, from $64 \mathrm{~K}$ for $\mathrm{B}=0.01 \mathrm{~T}$ to $90 \mathrm{~K}$ for $\mathrm{B}=5 \mathrm{~T}$, as shown in the inset of Figure 2(a). The magnetic structure of $\mathrm{TbMn}_{2} \mathrm{Si}_{2}$ has been well studied using neutron diffraction reported earlier by Shigeoka et al. ${ }^{25}$ and Kolenda $e t a l .{ }^{26}$ There are three different magnetic phases in the temperature range below $300 \mathrm{~K}$, i.e., the ferromagnetic mixed commensurate structure plus the ferromagnetic structure of terbium [Fmc(II) $+\mathrm{F}(\mathrm{Tb})]$, the antiferromagnetic interlayer plus ferromagnetic structure of terbium $[\mathrm{AFil}+\mathrm{F}(\mathrm{Tb})]$ type, and the antiferromagnetic interlayer (AFil), as shown in Figure 2(b). $T_{\mathrm{cl}}$ here is defined as the critical temperature where the magnetic state begins to make a transition from [Fmc(II) $+\mathrm{F}(\mathrm{Tb})]$ phase to $[\mathrm{AFil}+\mathrm{F}(\mathrm{Tb})]$ phase with increasing temperature, while $T_{\mathrm{c} 2}$ represents the critical temperature where the magnetic state finally makes a transition from $[\mathrm{AFil}+\mathrm{F}(\mathrm{Tb})]$ phase to AFil phase with increasing temperature. The fact that $\mathrm{T}_{\mathrm{c} 1}$ and $\mathrm{T}_{\mathrm{c} 2}$ matches well with the temperature for the change in shape of the unit cell, as shown in Figures 1(c) and 1(d), indicates that these transitions around $\mathrm{T}_{\mathrm{c} 1}$ and $\mathrm{T}_{\mathrm{c} 2}$ are first order type. This indicates that the application of magnetic field can significantly modify the magnetic states and broaden the temperature range between $\mathrm{T}_{\mathrm{c} 1}$ and $\mathrm{T}_{\mathrm{c} 2}$. By comparison, a recent work on $\mathrm{TbMn}_{2} \mathrm{Si}_{2}$ also reported similar transitions but with slightly different values of $T_{c 1}(46 K)$ and $T_{c 2}(68 K) .{ }^{18}$ This was attributed to the nonstoichiometric ratio caused by uncontrollable loss of manganese.

The magnetization curves obtained for $\mathrm{TbMn}_{2} \mathrm{Si}_{2}$ for fields in the range of $0-5 \mathrm{~T}$ around its transition temperatures are shown in Figure 3(a). These data were obtained for increasing field at $3 \mathrm{~K}$ intervals spanning the range from $40 \mathrm{~K}$ to $100 \mathrm{~K}$ covering $\mathrm{T}_{\mathrm{c} 1}$ and $\mathrm{T}_{\mathrm{c} 2}$. The corresponding Arrott plots of $\mathrm{M}^{2}$ versus $\mu_{0} \mathrm{H} / \mathrm{M}$ were derived and are shown in Figure 3(b). The S-shaped nature of the Arrott plot near $T_{c 2}$ denotes the negative sign of the coefficient $c_{2}(T)$ in the Landau expansion of the magnetic free energy, confirming the characteristic of a first order magnetic transition. ${ }^{18}$
The $-\Delta \mathrm{S}_{\mathrm{M}}$ of the sample was calculated from the magnetization isotherm curves in Figure 3(a) using an integral version of Maxwell's thermodynamic relation

$$
\Delta S_{M}(T, H)=\int_{0}^{H^{\max }}\left(\frac{\partial M(H, T)}{\partial T}\right)_{H} d H .
$$

The plots of the temperature dependence of $-S_{M}$ for different magnetic field changes from 1 to $5 \mathrm{~T}$ are shown in Figure 4(a). All of these plots have two peaks located around $T_{c 1}$ and $\mathrm{T}_{\mathrm{c} 2}$, corresponding to the two magnetic phase transitions of $\mathrm{TbMn}_{2} \mathrm{Si}_{2}$. Because the two peaks are so close, $\mathrm{TbMn}_{2} \mathrm{Si}_{2}$ can be used over a wide range of temperature for magnetic refrigerators and has a huge refrigerant capacity (RC). The value of $\mathrm{RC}$ can be determined as the product of $-\Delta \mathrm{S}_{\mathrm{M}}{ }^{\mathrm{max}}$ and the full width at half maximum (FWHM) in the $-\Delta \mathrm{S}_{\mathrm{M}}(\mathrm{T})$ curve. The values of RC are evaluated to be as large as 59.8 and $396 \mathrm{~J} / \mathrm{kg}$ for field changes of $0-2 \mathrm{~T}$ and $0-5 \mathrm{~T}$, respectively. These values are comparable to or larger than those of recently reported materials such as $\mathrm{TmCuAl}(372 \mathrm{~J} / \mathrm{kg}$ at $4 \mathrm{~K})$, $\mathrm{ErMn}_{2} \mathrm{Si}_{2}(365 \mathrm{~J} / \mathrm{kg}$ at $4.5 \mathrm{~K}), \operatorname{ErRuSi}(416 \mathrm{~J} / \mathrm{kg}$ at $9 \mathrm{~K})$, $\mathrm{DyNi}_{2} \mathrm{~B}_{2} \mathrm{C}(290 \mathrm{~J} / \mathrm{kg}$ at $12 \mathrm{~K}), \mathrm{TmGa}(364 \mathrm{~J} / \mathrm{kg}$ at $16 \mathrm{~K})$, and $\mathrm{Ho}_{2} \mathrm{PdSi}_{3}(427 \mathrm{~J} / \mathrm{kg}$ at $9 \mathrm{~K})$ for a field change of $0-5 \mathrm{~T}^{29}$

The corresponding adiabatic temperature change, $\Delta \mathrm{T}_{\mathrm{ad}}(\mathrm{T})$, can be evaluated from $-\Delta \mathrm{S}_{\mathrm{M}}(\mathrm{T}, \mathrm{B})$ and the zero-field heat capacity data (described below). ${ }^{22,30}$ The peak value of the adiabatic temperature change is $\Delta T_{\text {maxad }} \approx 7.5 \mathrm{~K}$ for a field change of $0-5 \mathrm{~T}$, as shown in Figure 4(b).

The temperature dependence of the resistance of $\mathrm{TbMn}_{2} \mathrm{Si}_{2}$ at zero magnetic fields is shown in Figure 5(a), which is quite similar to previously reported result. ${ }^{31}$ The pronounced anomaly observed around $\mathrm{T}_{\mathrm{c} 1}$ and $\mathrm{T}_{\mathrm{c} 2}$ originates from the coincidence of the structural and magnetic phase transitions. A little hysteresis has been observed for the heating and cooling processes, as shown in the inset of Figure 5(a). This is in accordance with the hysteresis behaviour of the magnetization of $\mathrm{TbMn}_{2} \mathrm{Si}_{2}$ with a first order phase transition. The magnetic phase transition temperatures

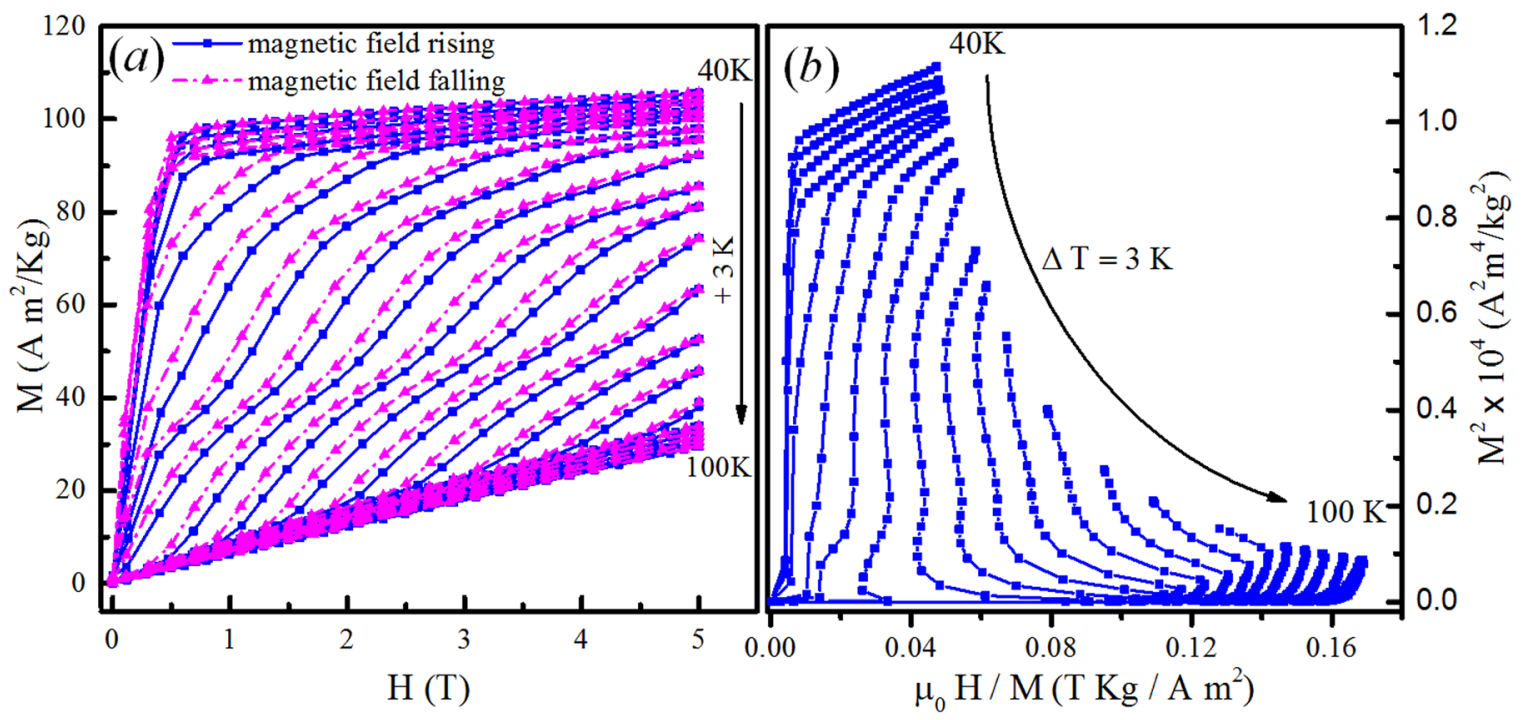

FIG. 3. (a) Magnetization curves for $\mathrm{TbMn}_{2} \mathrm{Si}_{2}$ over the temperature range of $48-100 \mathrm{~K}$ for increasing (solid line) and decreasing (dashed-dotted line) field and (b) the corresponding Arrott plots of $\mathrm{M}^{2}$ versus $\mu_{\mathrm{o}} \mathrm{H} / \mathrm{M}$. 


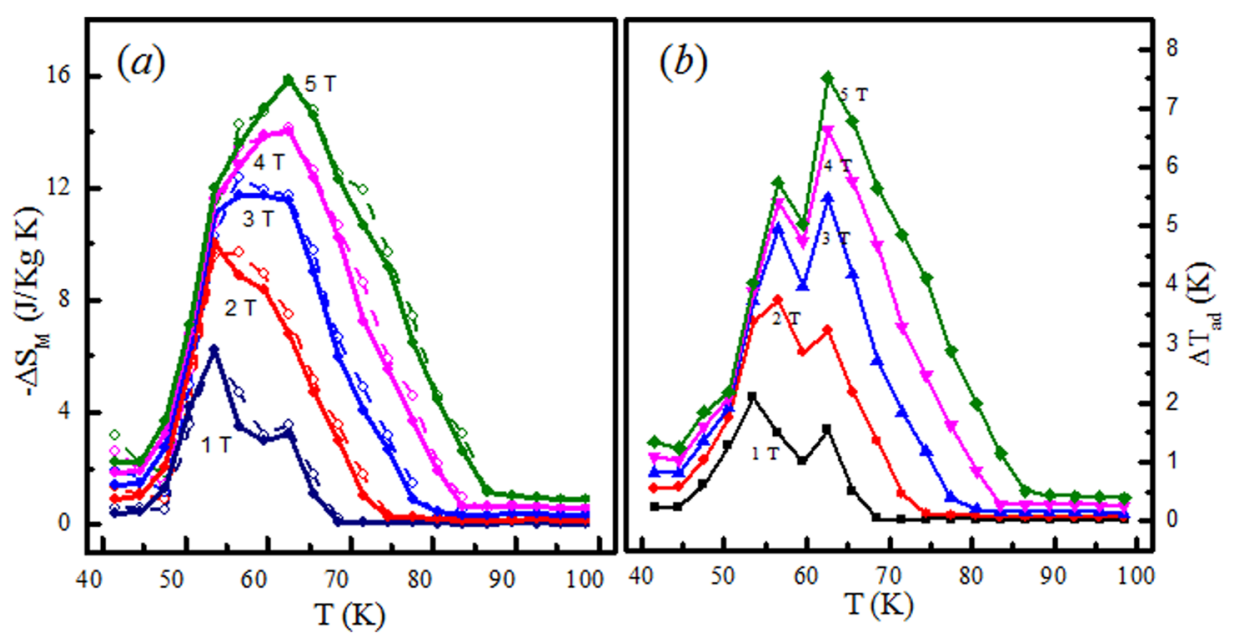

FIG. 4. (a) Magnetic entropy change, $-\Delta \mathrm{S}_{\mathrm{M}}(\mathrm{T}, \mathrm{H})$ for $\mathrm{TbMn}_{2} \mathrm{Si}_{2}$ calculated from magnetization isotherms in Figure 3(a). (b) The corresponding adiabatic temperature change, $\Delta \mathrm{T}_{\mathrm{ad}}(\mathrm{T})$, evaluated from $-\Delta \mathrm{S}_{\mathrm{M}}(\mathrm{T}, \mathrm{B})$ and the zero field heat capacity data.
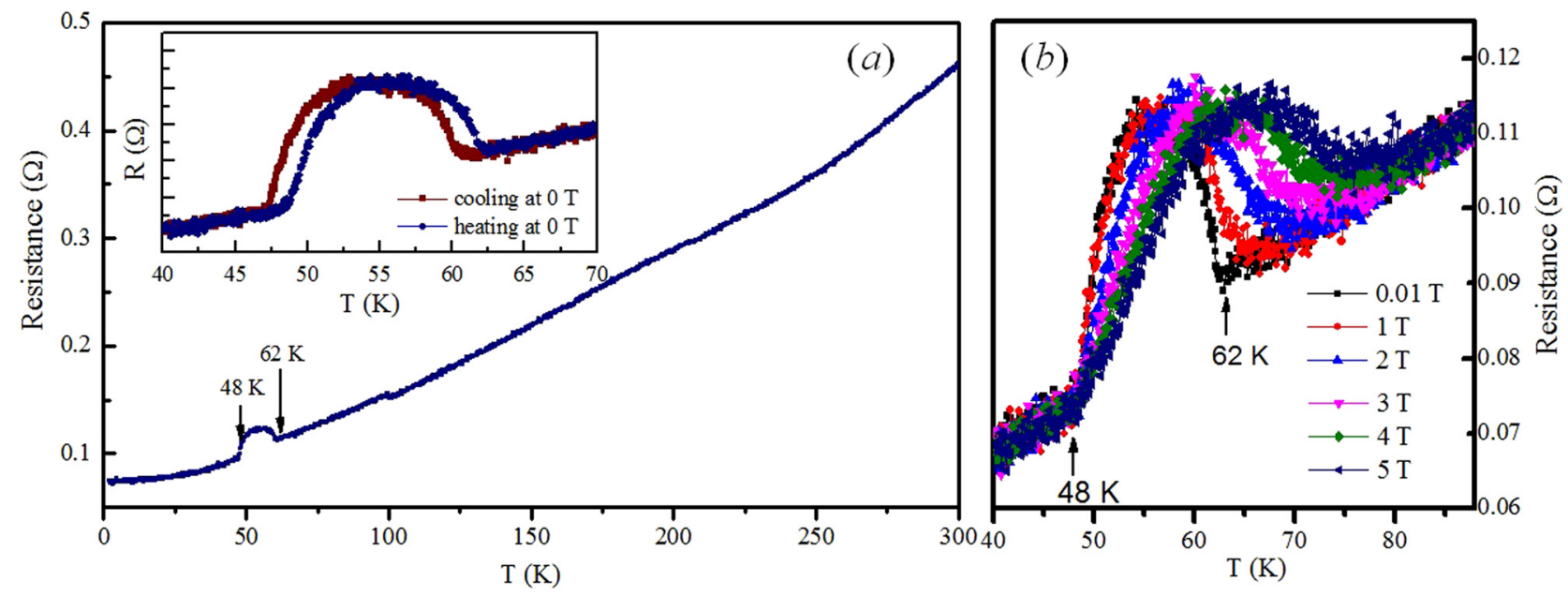

FIG. 5. Temperature dependence of the resistance of $\mathrm{TbMn}_{2} \mathrm{Si}_{2}$ : (a) measured at zero field with temperature increasing; and the inset shows the difference between the cooling process and the heating process from 40 to $70 \mathrm{~K}$; (b) measured at magnetic fields of 0-5 T with temperature increasing after zero field cooling.

obtained by transport measurements are $48 \mathrm{~K}$ and $62 \mathrm{~K}$, respectively; it is interesting to learn from these measurements that the application of external magnetic field can broaden this transport anomaly temperature range, with the starting temperature almost unchanging, while the ending temperature shifts higher, as shown in Figure 4(c). This phenomenon agrees well with $\mathrm{T}_{\mathrm{c} 2}$ being affected by magnetic field, while $\mathrm{T}_{\mathrm{c} 1}$ is almost unaffected in magnetic measurements.

The temperature dependence of the heat capacity measurements $\mathrm{C}_{\mathrm{p}}(\mathrm{T})$ for the $\mathrm{TbMn}_{2} \mathrm{Si}_{2}$ in the temperature range of $4-100 \mathrm{~K}$ is shown in Figure 6. The pronounced anomaly observed around $\mathrm{T}_{\mathrm{c} 1}$ and $\mathrm{T}_{\mathrm{c} 2}$ originates from the coincidence of the structural and magnetic phase transitions. It is well accepted that phonons, $\mathrm{C}_{\mathrm{ph}}(\mathrm{T})$, electrons, $\mathrm{C}_{\mathrm{el}}(\mathrm{T})$, and magnons, $\mathrm{C}_{\mathrm{m}}(\mathrm{T})$, are the three key objects contributing heat capacity to $\mathrm{C}_{\mathrm{p}}(\mathrm{T})$. At lower temperatures, the heat capacity can be described as

$$
C_{p}(T)=\gamma T+\beta T^{3},
$$

where $\gamma \mathrm{T}$ represents the contribution of electrons and $\beta \mathrm{T}^{3}$ comes from the contribution of phonons. By fitting the graph of $C_{p} / T$ versus $T^{2}$ at lower temperatures $(\leq 10 \mathrm{~K})$, as shown in the inset of Figure 6, the values of $\gamma=28.1 \mathrm{~mJ} / \mathrm{molK}^{2}$ and $\beta=2.52 \times 10^{-4} \mathrm{~J} / \mathrm{molK}^{4}$ have been derived. The Debye temperature $\theta_{\mathrm{D}}$ can be obtained to be $\theta_{\mathrm{D}}=337( \pm 10) \mathrm{K}$ from the $\beta$ value (using $\theta_{\mathrm{D}}=\left(12 \pi^{4} \mathrm{k}_{\mathrm{B}} / 5 \beta\right)^{1 / 3}$, where $\mathrm{k}_{\mathrm{B}}$ is the Boltzmann constant). The density of states at the Fermi level, $\mathrm{N}\left(\mathrm{E}_{\mathrm{F}}\right)$, can be derived from the values of $\gamma$, using

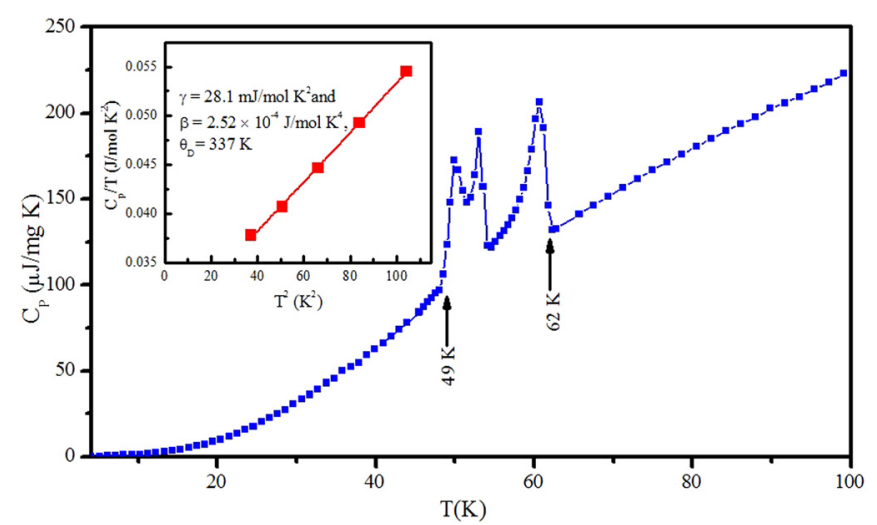

FIG. 6. Temperature dependence of the heat capacity $\mathrm{C}_{\mathrm{p}}$ for $\mathrm{TbMn}_{2} \mathrm{Si}_{2}$ for the temperature range of $4-100 \mathrm{~K}$; and the inset shows $\mathrm{C}_{\mathrm{p}} / \mathrm{T}$ versus $\mathrm{T}^{2}$ at temperatures below $10 \mathrm{~K}$. 
$\mathrm{N}\left(\mathrm{E}_{\mathrm{F}}\right)=3 \gamma / \mathrm{k}_{\mathrm{B}}^{2} \pi^{2}$, to be $2.38 \mathrm{eV}^{-1}$ atom $^{-1}$, which is larger than the values obtained for $\mathrm{YMn}_{2} \mathrm{Si}_{2}\left(1.47 \mathrm{eV}^{-1}\right.$ atom $\left.{ }^{-1}\right)$ and $\mathrm{LaMn}_{2} \mathrm{Si}_{2}\left(1.78 \mathrm{eV}^{-1}\right.$ atom $\left.{ }^{-1}\right)$, but smaller than the value for $\mathrm{YbMn}_{2} \mathrm{Si}_{2}\left(4.0 \mathrm{eV}^{-1}\right.$ atom $\left.{ }^{-1}\right){ }^{32}$

To summarize, the structural and physical properties of $\mathrm{TbMn}_{2} \mathrm{Si}_{2}$ alloy were studied. The results confirmed a magneto-elastic coupling around two successive magnetic transitions in this alloy. Based on this coupling, $\mathrm{TbMn}_{2} \mathrm{Si}_{2}$ alloy exhibits a magneto-volume effect and a table-like magnetocaloric effect. The table-like magnetocaloric effect based on two successive magnetic phase transitions shows a large net magnetic refrigerant capacity, suggesting that $\mathrm{TbMn}_{2} \mathrm{Si}_{2}$ alloy is attractive potential magnetocaloric material for low temperature magnetic refrigeration. Moreover, the Debye temperature and the density of states $N\left(E_{F}\right)$ at the Fermi level have been determined and analysed from the heat capacity.

This work was supported in part by Australia Research Council Discovery Grant Nos. DP0879070 and DP110102386. Z. X. Cheng thanks Australia Research Council for Future Fellowship (FT0990391). All the authors thank Dr. T. Silver for polishing English.

${ }^{1}$ V. K. Pecharsky and K. A. Gschneidner, Jr., Phys. Rev. Lett. 78, 4494 (1997).

${ }^{2}$ V. K. Pecharsky and K. A. Gschneidner, Jr., Adv. Cryog. Eng. 43, 1729 (1998).

${ }^{3}$ O. Tegus, E. Brück, K. H. J. Buschow, and F. R. de Boer, Nature 415, 150 (2002).

${ }^{4}$ E. Brück, J. Phys. D: Appl. Phys. 38, R381 (2005).

${ }^{5}$ J. Gass, D. J. Rebar, G. T. Woods, H. Srikanth, and G. S. Nolas, J. Appl. Phys. 99, 08K902 (2006).

${ }^{6}$ J. Shen, J. L. Zhao, F. X. Hu, J. F. Wu, J. R. Sun, and B. G. Shen, Chin. Phys. B 19, 047502 (2010).

${ }^{7}$ J. Liu, T. Gottschall, K. P. Skokov, J. D. Moore, and O. Gutfleisch, Nat. Mater. 11, 620 (2012).

${ }^{8}$ P. Shamba, J. L. Wang, J. C. Debnath, S. J. Kennedy, R. Zeng, M. F. Md Din, F. Hong, Z. X. Cheng, A. J. Studer, and S. X. Dou, J. Phys.: Condens. Matter 25, 056001 (2013).
${ }^{9}$ F. Casanova, X. Batlle, A. Labarta, J. Marcos, L. Manosa, and A. Planes, J. Appl. Phys. 93, 8313 (2003).

${ }^{10}$ Y. I. Spichkin and A. M. Tishin, J. Alloys Compd. 403, 38 (2005).

${ }^{11}$ M. I. Il'in, Yu. I. Spichkin, V. V. Surikov, and A. M. Tishin, Bull. Russ. Acad. Sci.: Phys. 71, 1528 (2007).

${ }^{12}$ N. K. Sun, W. B. Cui, D. Li, D. Y. Geng, F. Yang, and Z. D. Zhang, Appl. Phys. Lett. 92, 072504 (2008).

${ }^{13}$ J. D. Zou, B. G. Shen, B. Gao, J. Shen, and J. R. Sun, Adv. Mater. 21, 693 (2009).

${ }^{14}$ J. D. Moore, K. Morrison, K. G. Sandeman, M. Katter, and L. F. Cohen, Appl. Phys. Lett. 95, 252504 (2009).

${ }^{15}$ Y. L. Wu, O. Tegus, W. G. Zhang, S. Yiriyoltu, and B. M. Songlin, Acta Metall. Sinica (Engl. Lett.) 22, 397 (2009).

${ }^{16}$ J. Shen, B. Gao, H. W. Zhang, F. X. Hu, Y. X. Li, J. R. Sun, and B. G. Shen, Appl. Phys. Lett. 91, 142504 (2007).

${ }^{17}$ P. Shamba, J. C. Debnath, R. Zeng, J. L. Wang, S. J. Campbell, S. J. Kennedy, and S. X. Dou, J. Appl. Phys. 113, 17A941 (2013).

${ }^{18}$ B. Maji, M. K. Ray, K. G. Suresh, and S. Banerjee, J. Appl. Phys. 116, 213913 (2014).

${ }^{19}$ L. W. Li, O. Niehaus, M. Kersting, and R. Pöttgen, Appl. Phys. Lett. 104, 092416 (2014).

${ }^{20}$ A. Chaturvedi, S. Stefanoski, M. H. Phan, G. S. Nolas, and H. Srikanth, Appl. Phys. Lett. 99, 162513 (2011).

${ }^{21}$ L. W. Li, T. Namiki, D. X. Huo, Z. H. Qian, and K. Nishimura, Appl. Phys. Lett. 103, 222405 (2013).

${ }^{22}$ J. L. Wang, S. J. Campbell, J. M. Cadogan, A. J. Studer, R. Zeng, and S. X. Dou, Appl. Phys. Lett. 98, 232509 (2011).

${ }^{23}$ T. Samanta, I. Das, and S. Banerjee, Appl. Phys. Lett. 91, 152506 (2007).

${ }^{24}$ J. L. Wang, L. Caron, S. J. Campbell, S. J. Kennedy, M. Hofmann, Z. X. Cheng, M. F. Md. Din, A. J. Studer, E. Brück, and S. X. Dou, Phys. Rev. Lett. 110, 217211 (2013).

${ }^{25}$ T. Shigeoka, N. Iwata, H. Fujii, and T. Okamoto, J. Magn. Magn. Mater. 54-57, 1343 (1986).

${ }^{26}$ M. Kolenda, J. Leciejewicz, A. Szytula, N. Stüsser, and Z. Tomkowicz, J. Alloys Compd. 241, L1 (1996).

${ }^{27}$ F. Sayetat, P. Fertey, and M. Kessler, J. Appl. Crystallogr. 31, 121 (1998).

${ }^{28}$ J. L. Wang, A. J. Studer, S. J. Campbell, M. Hofmann, and J. M. Cadogan, Physica B 385, 326 (2006).

${ }^{29}$ J. M. Zhao, J. Shen, L. Q. Yan, X. Q. Gao, C. C. Tang, J. F. Wu, J. R. Sun, and B. G. Shen, J. Alloys Compd. 618, 512 (2015).

${ }^{30}$ M. F. Md. Din, J. L. Wang, S. J. Campbell, A. J. Studer, and M. Avdeev, Appl. Phys. Lett. 104, 042401 (2014).

${ }^{31}$ S. A. Granovsky, I. Y. Gaidukova, M. Doerr, M. Loewenhaupt, and A. S. Markosyan, J. Magn. Magn. Mater. 290, 615 (2005).

${ }^{32}$ A. Szytüa, A. Jezierski, B. Penc, M. Hofmann, and S. J. Campbell, J. Alloys Compd. 363, 47 (2004). 